\title{
Refractive properties of the healthy human eye during acute hyperglycemia
}

\author{
Nanouk G. M. Wiemer • Elisabeth M. W. Eekhoff • \\ Suat Simsek • Robert J. Heine • Peter J. Ringens • \\ Bettine C. P. Polak • Michiel Dubbelman
}

Received: 4 December 2007 /Revised: 20 February 2008 / Accepted: 26 February 2008 / Published online: 4 April 2008

(C) The Author(s) 2008

\begin{abstract}
Purpose To measure the refractive properties of the healthy human eye during acute hyperglycemia by means of Scheimpflug imaging and Hartmann-Shack aberrometry. Methods Acute hyperglycemia was induced in five healthy subjects (two males, three females, mean age $\pm \mathrm{SD}$ 24.8 years \pm 4.6 ) by means of an oral glucose tolerance test (OGTT) after subcutaneous somatostatin injection. Before and every 30 minutes after the OGTT, measurements with Scheimpflug imaging and Hartmann-Shack aberrometry were performed. The main outcome measures were the thickness and shape of the lens, and the ocular refractive error and higher order aberrations. The equivalent refractive index of the lens was calculated from these parameters. Measurements at baseline and during hyperglycemia were analyzed by means of Wilcoxon signed rank sum tests.
\end{abstract}

N. G. M. Wiemer $(\bowtie) \cdot$ P. J. Ringens $\cdot$ B. C. P. Polak Department of Ophthalmology, VU University Medical Center, P.O. Box 7057, 1007 MB, Amsterdam, The Netherlands

e-mail: ngm.wiemer@vumc.nl

N. G. M. Wiemer ' E. M. W. Eekhoff - S. Simsek - R. J. Heine • P. J. Ringens $\cdot$ B. C. P. Polak $\cdot$ M. Dubbelman Institute for Research in Extramural Medicine, VU University Medical Center,

Amsterdam, the Netherlands

E. M. W. Eekhoff $\cdot$ S. Simsek $\cdot$ R. J. Heine

Department of Endocrinology, VU University Medical Center, Amsterdam, the Netherlands

\section{Dubbelman}

Department of Physics and Medical Technology,

VU University Medical Center,

Amsterdam, the Netherlands
Results During hyperglycemia (mean blood glucose level at baseline: $4.0 \mathrm{mmol} / \mathrm{l}$; mean maximal blood glucose level: $18.4 \mathrm{mmol} / \mathrm{l})$ no changes could be found in the refractive properties within the group. In one subject, a hyperopic shift $(0.4 \mathrm{D})$ was observed, together with a more convex shape of the anterior lens surface and a decrease in the equivalent refractive index of the lens.

Conclusions This study shows that hyperglycemia generally does not cause changes in the refractive properties of the healthy eye. Nevertheless, in one subject a hyperopic shift accompanied by a change in shape and refractive index of the lens was measured. This finding could provide an explanation for the mechanism underlying the refractive changes that are often observed during hyperglycemia.

Keywords Hyperglycemia · Diabetes mellitus .

Scheimpflug imaging · Hartmann-Shack aberrometry .

Refractive errors · Lens

Transient refractive changes, due to a variation in blood glucose levels, are well-known complications of diabetes mellitus (DM). Both myopic shifts $[2,6,10,23,31,36]$ and hyperopic shifts $[9,13,18,26,32,37]$ have been reported in patients with DM after several days or weeks of hyperglycemia. It has been suggested that the predominant cause of the refractive changes is a change in the thickness of the lens [16, 17, 19, 25, 29] or shape of the lens [21], and/or a change in its refractive index [24, 27, 29, 33]. Two studies have been conducted in which hyperglycemia was induced under controlled circumstances to investigate refractive changes during hyperglycemia. Firstly, Gwinup et al. [15] administered glucose intravenously to ten patients with DM. A myopic shift of maximal $-0.75 \mathrm{D}$ was measured with autorefractometry. Secondly, Furushima et al. [11] induced hyperglycemia in seven healthy, young 
subjects through somatostatin injections and an oral glucose load. By means of autorefractometry and ultrasound biometry a large change in ocular refraction (-2.0 diopters (D)) and thickness of the lens $(1.0 \mathrm{~mm})$ was measured within 150 minutes after administration of the glucose load (maximal hyperglycemia: $13.9 \mathrm{mmol} / \mathrm{l}$ ). The results of these two studies indicated that induced hyperglycemia can cause changes in refraction and that these changes appeared to be larger in healthy subjects.

In the study of Furushima et al. [11], only the thickness of the lens was measured, and there is no information about the change in the shape and the refractive index of the lens due to acute hyperglycemia. Therefore, the aim of our study was to induce hyperglycemia in healthy subjects under controlled circumstances, and accurately measure ocular geometry and refraction by means of corrected Scheimpflug imaging and Hartmann-Shack aberrometry, in order to investigate the mechanism underlying refractive changes during hyperglycemia. From the ocular geometry and refraction, in combination with the measurement of the axial length of the eye, it is also possible to calculate the equivalent refractive index of the lens $[4,5]$.

\section{Subjects and methods}

Five healthy Caucasian subjects (two males and three females) were recruited for this study. Mean age was 24.8 years ( $\mathrm{SD} \pm 4.6$ and range $21.2-32.6$ ) and mean body mass index (BMI) was $24.2 \mathrm{~kg} / \mathrm{m} 2(\mathrm{SD} \pm 3.2$ and range 21.4 - 29.7). The Medical Ethics Committee of the VU University Medical Center in Amsterdam approved the study protocol, and written informed consent was obtained from all subjects after the nature of the study had been explained. Subjects with a history of diabetes mellitus (or a fasting plasma glucose $>5.5 \mathrm{mmol} / \mathrm{l}$ ), a BMI of $>30 \mathrm{~kg} / \mathrm{m} 2$, visual acuity of $<0.5$ (Snellen), or a history of ocular pathology were excluded from the study.

Procedure to induce hyperglycemia

After a 10-hour overnight fast, the subjects received a subcutaneous injection of $100 \mu \mathrm{g}$ synthetic somatostatin (Sandostatin, Novartis, Basel, Switzerland) in order to suppress the endogenous insulin secretion during glucose loading. Each subject had an oral glucose tolerance test (OGTT) (glucose $75 \mathrm{~g}) 30$ minutes after the somatostatin injection. Blood glucose levels were measured with a blood glucose analyzer (HemoCue Diagnostics BV, Oisterwijk, the Netherlands). Endogenous insulin levels were determined with immunometric assays (Luminescence, Bayer Diagnostics, Mijdrecht, the Netherlands) in the Laboratory of Endocrinology of the Department of Clinical Chemistry in the VU University Medical Center. The subjects remained in a fasting state during the entire procedure.

\section{Measurement of ocular parameters}

Before and 120 minutes after the OGTT, $1.0 \%$ cyclopentolate and $5.0 \%$ phenylephrine eye-drops were administered to the right eye of the subjects. Hartmann-Shack aberrometry was performed with an IRX3 aberrometer (Imagine Eye Optics, Paris, France) and Scheimpflug imaging was performed with a Topcon SL-45 Scheimpflug camera, in which the film was replaced by a charge-coupled device (CCD) camera (St-9XE, SBIG astronomical instruments) with a range of 16 bits of grey values $(512 \times 512$ pixels, pixel size $20 \times 20 \mu \mathrm{m}$, magnification: $1 \times$ ). Before and every 30 minutes after the OGTT, three measurements were made with each apparatus. To obtain accurate measurements of the shape of the lens, ray-tracing was performed to correct the Scheimpflug images for the distortion that is inherent to this technique $[4,5]$. By combining the measurements of the corneal thickness (d1), the depth of the anterior chamber (ACD), the anterior (R1) and posterior (R2) radius of the cornea, the lens thickness (d3) and the anterior (R3) and posterior (R4) radius of the lens, the axial length of the eye, and ocular refraction, it was possible to calculate the equivalent refractive index of the lens ( $\mathrm{n}_{\text {lens }}$ ) by means of an iterative process [5]. In these calculations it was assumed that the refractive indices of the cornea, aqueous humor, and vitreous do not change, because in vitro experiments have shown that large changes in glucose levels induce negligible changes in the refractive indices of the ocular media $[8,22]$. The axial length of the eye was measured with an IOL-master (Carl Zeiss Inc., North America). The equivalent refractive error (ERE) was calculated as: $\mathrm{ERE}=$ sphere $+($ cylinder/2). Furthermore, the higher order aberrations (HOA) of each eye were analyzed for a pupil size of $5.7 \mathrm{~mm}$ and they were summarized in root mean square errors (RMS), including the third up to the eighth Zernike orders [34]. Furthermore, the HOA, including the spherical aberrations, were analyzed separately.

Measurements at baseline and during hyperglycemia were compared in the whole group by means of Wilcoxon signed rank sum tests. A refractive change of more than $0.2 \mathrm{D}$ and a change in HOA of more than $0.025 \mu \mathrm{m}$ were considered to be meaningful, according to the precision (defined as $95 \%$ confidence interval) for measuring the ERE and HOA of the aberrometer [3, 30]. Error analysis indicated that a change in R1, R2, d1, ACD, d3, R3, R4, and $\mathrm{n}$ lens of more than $0.05 \mathrm{~mm}, 0.05 \mathrm{~mm}, 0.02 \mathrm{~mm}$, $0.14 \mathrm{~mm}, 0.15 \mathrm{~mm}, 0.30 \mathrm{~mm}$ and $0.40 \mathrm{~mm}$, and 0.007 respectively, could be considered as significant, according to the precision of corrected Scheimpflug imaging [4]. In 
each subject individually, the significance of a change was determined from the precision of the measurements and the difference in the ocular parameters at baseline and during hyperglycemia. $P$ values $\leq 0.05$ were considered statistically significant.

\section{Results}

Figure 1 shows the changes in blood glucose after the OGTT. In all subjects the mean blood glucose levels rose from $4.0 \mathrm{mmol} / \mathrm{l}$ (range $3.4-4.5 \mathrm{mmol} / \mathrm{l}$ ) to $18.4 \mathrm{mmol} / \mathrm{l}$ (range $16.1-22.0 \mathrm{mmol} / \mathrm{l}$ ) in 126 minutes (range 90-210 minutes) after the OGTT. Subject 1 had a delayed elevation of blood glucose level, and therefore this subject received a second $75 \mathrm{~g}$ oral glucose load at time $=30$ minutes. Furthermore, venous blood samples of subject 1 were taken from the antecubital vein, which was kept open with $0.9 \%$ saline $(100 \mathrm{cl})$. Endogenous insulin was suppressed by the subcutaneous injection of somatostatin during the glucose load to a mean value of $2.1 \mathrm{pmol} / 1$ (range $0.4-4.5 \mathrm{pmol} / \mathrm{l}$ ), and remained below basal secretion level $(<110.0 \mathrm{pmol} / \mathrm{l})$ for 147 minutes (range 75-270 minutes).

No significant change in ERE was found in the whole group or in four of the subjects individually. In subject 1 , a hyperopic shift in ERE of $0.4 \mathrm{D}$ and an increase in the spherical aberration $( \pm \mathrm{SE})$ from $0.03 \pm 0.01 \mu \mathrm{m}$ at $\mathrm{T}=0$ to $0.11 \pm 0.01 \mu \mathrm{m}$ during hyperglycemia was measured $(p<$ 0.001 ). The other HOA did not change in subject 1 . Furthermore, there was no significant change in the HOA separately or the RMS values in the group or in any of the other subjects individually. No changes in corneal thickness (d1), corneal shape (R1 and R2), anterior chamber depth (ACD), lens thickness (d3), or posterior lens shape (R4) were found in the group or in any of the subjects individually. In the whole group and in four subjects, no changes were found in the anterior radius of the lens (R3)

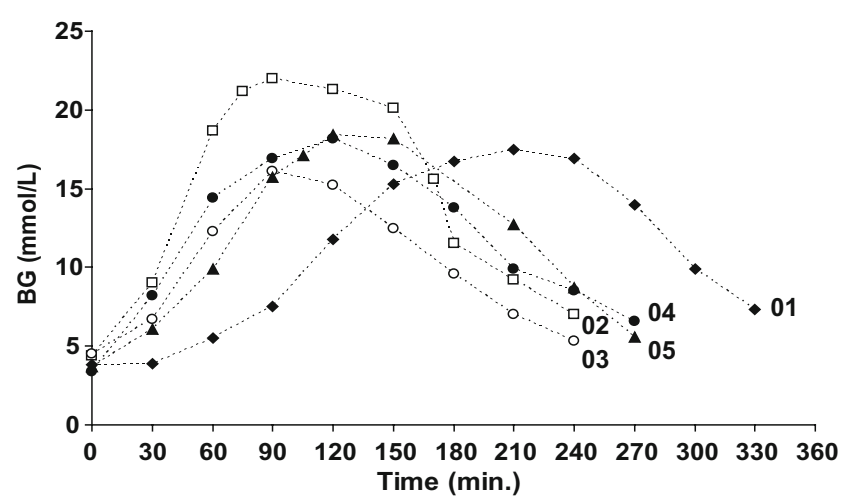

Fig. 1 Changes in blood glucose (BG) levels in the five subjects after the administration of somatostatin and glucose; the oral glucose load $(75 \mathrm{~g})$ was administered at time $=0$ minutes or refractive index ( $\mathrm{n}_{\text {lens }}$ ). However, in subject 01, the R3 and $\mathrm{n}$ lens changed significantly during hyperglycemia, compared to normal conditions; R3 decreased from 11.65 to $9.69 \mathrm{~mm}$ (mean decrease $\mathrm{R} 3=1.96 \mathrm{~mm} ; \mathrm{p}<0.001$ ) and $\mathrm{n}$ lens decreased from 1.436 to 1.422 (mean decrease $\mathrm{n}$ lens $=$ $0.014 ; \mathrm{p}=0.003)$. Figure 2 presents graphs of the normalized ERE, ACD, d3, R3, R4 and $\mathrm{n}_{\text {lens }}$ of the five subjects. Figure 3 shows two corrected Scheimpflug images and a schematic drawing of the lens of subject 1 , in order to illustrate the differences in lens geometry during hyperglycemia compared to baseline. In all subjects, both hematological and ocular parameters normalized within 6 hours after the OGTT.

\section{Discussion}

Refractive changes occur frequently in patients with DM. The underlying mechanism is still unclear, and therefore the aim of our study was to measure ocular refraction and geometry during hyperglycemia, in an attempt to identify a possible explanation for these refractive changes. The effect of reproducible hyperglycemia was studied in healthy subjects without the systemic effects of DM. An OGTT in combination with a somatostatin injection was used to induce hyperglycemia. In an earlier study, this was shown to induce large changes in the refractive error and lens thickness [11]. Somatostatin inhibits insulin secretion [7], and to our knowledge there are no reports of refractive errors or changes in the lens due to this agent.

In general, and in four of the five subjects individually, no changes in ocular refraction or geometry were found during hyperglycemia. It could be that a more prolonged and severe hyperglycemia is needed to induce changes in refractive error or geometry of the eye. Glucose within the lens is metabolized via the sorbitol pathway, which consists of two enzymes that catalyze the conversion of glucose into its sugar alcohol sorbitol and the further conversion of sorbitol to fructose. These sugar alcohols tend to accumulate within the lens, because they penetrate cell membranes poorly. This accumulation of sugar alcohols causes the lens to swell [12]. This process might have taken longer than the observation period of the present study. Furthermore, the subjects measured in our study were young, and it could be that their lenses, which still have a fast metabolic reaction capacity, tolerate short hyperglycemic stress without swelling.

The results of our study are not in accordance with the findings of Furushima et al. [11], who observed a large myopic shift $(-2 \mathrm{D})$ and a large increase in the thickness of the lens $(1 \mathrm{~mm})$ during hyperglycemia in healthy subjects. It must be noted that in our study the mean increase in the blood glucose level was even higher than that of the study of Furushima et al.. One main difference between our study 
and the study by Furushima et al. is the methods that were used to measure ocular refraction (aberrometry versus autorefractometry) and ocular geometry (corrected Scheimpflug imaging versus ultrasound biometry). However, the precision of aberrometry and autorefractometry are comparable for the measurement of defocus, astigmatism and, consequently, the equivalent refractive error [3, 30, 35]. Furthermore, the precision of corrected Scheimpflug imaging and ultrasound biometry are comparable as well. It could be that the difference in ethnicity (Caucasian subjects in the present study versus Asian subjects in the study by Furushima et al.) caused the inconsistency between the two studies, since Asian people generally have a more myopic ocular refraction than Caucasian subjects [14, 38].
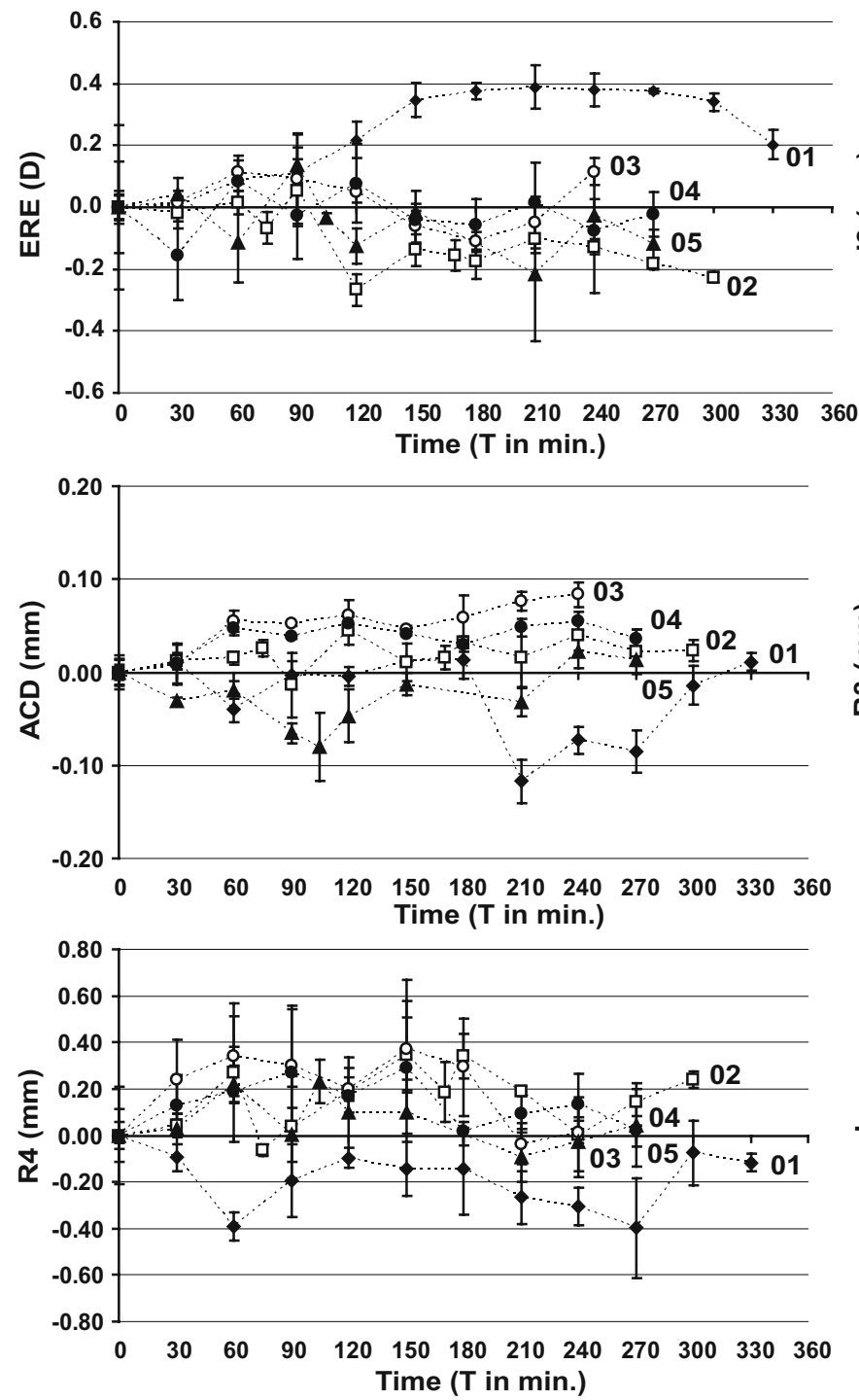

Fig. 2 Graphs of the normalized equivalent refractive error (ERE), lens thickness (d3), anterior chamber depth (ACD), anterior (R3) and posterior (R4) radius of the lens, and the refractive index of the lens ( $n_{\text {lens }}$ ) of the five subjects. Data are normalized by subtracting the
In our study, small but significant changes in ocular refraction and lens geometry were found in one subject. A hyperopic shift of $0.4 \mathrm{D}$ was found, in combination with an increase in anterior convexity of the lens. A combination of hyperopia and an increase in lens thickness during hyperglycemia has been described by Kluxen et al. [21], who found a $6 \mathrm{D}$ hyperopic shift and a $0.4 \mathrm{~mm}$ increase in lens thickness in a diabetic patient with hyperglycemia. Saito et al. [29] reported hyperopic shifts (1.1 to 4.9 D) and an increase of approximately $0.2 \mathrm{~mm}$ in the thickness of the lens in five diabetic subjects during hyperglycemia. Therefore, it has been suggested that hyperglycemia causes a change in the refractive index of the lens $[21,24,27,29$, 33]. The results of our study support this hypothesis; in
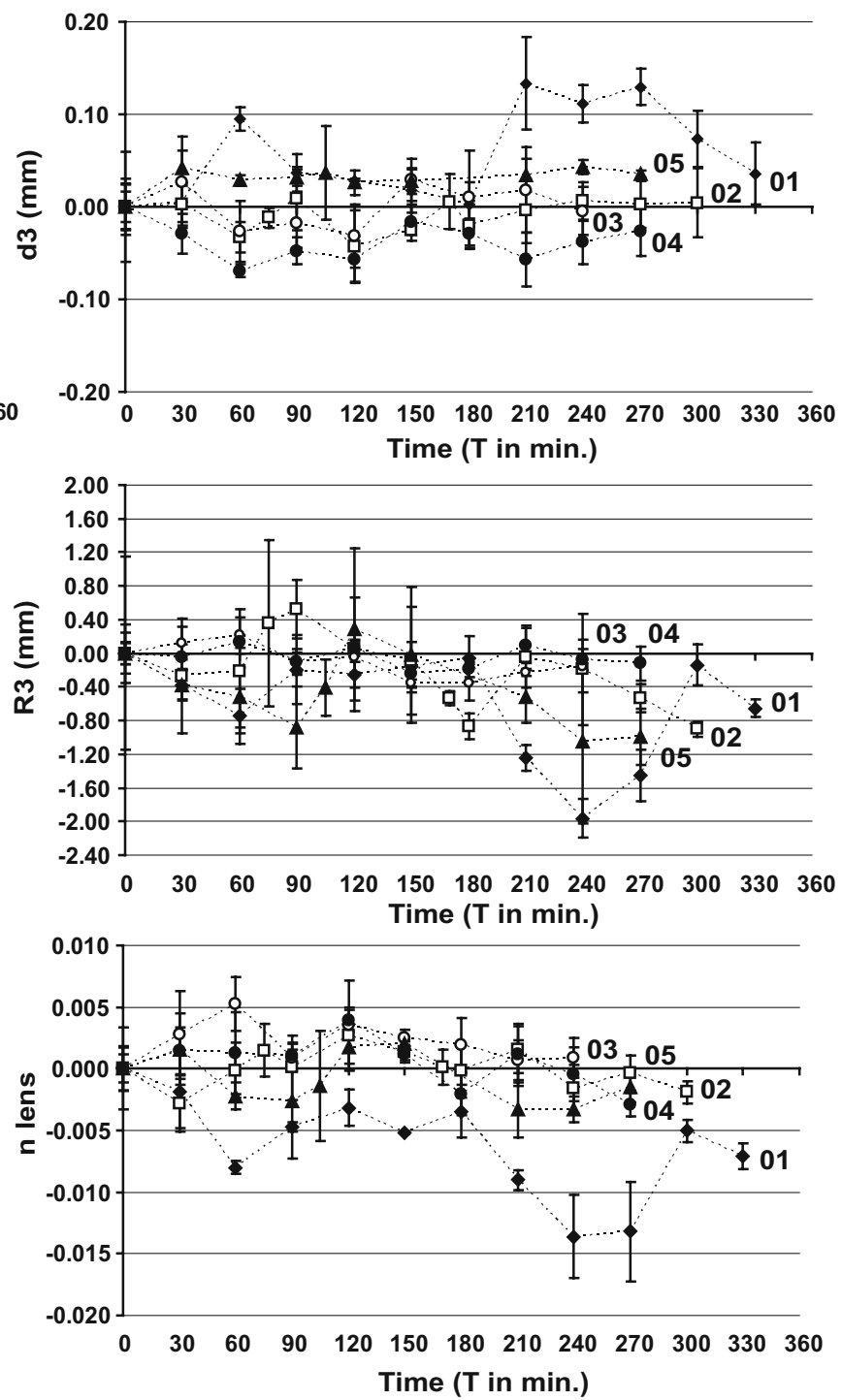

value at baseline from the measured value in each subject. In subject 01 a hyperopic shift of $0.4 \mathrm{D}$, an increase in R3 and decrease in $\mathrm{n}_{\text {lens }}$ were found during hyperglycemia at $\mathrm{T}=240$ minutes $(p<0.01)$. The oral glucose load was administered at $\mathrm{T}=0$ 

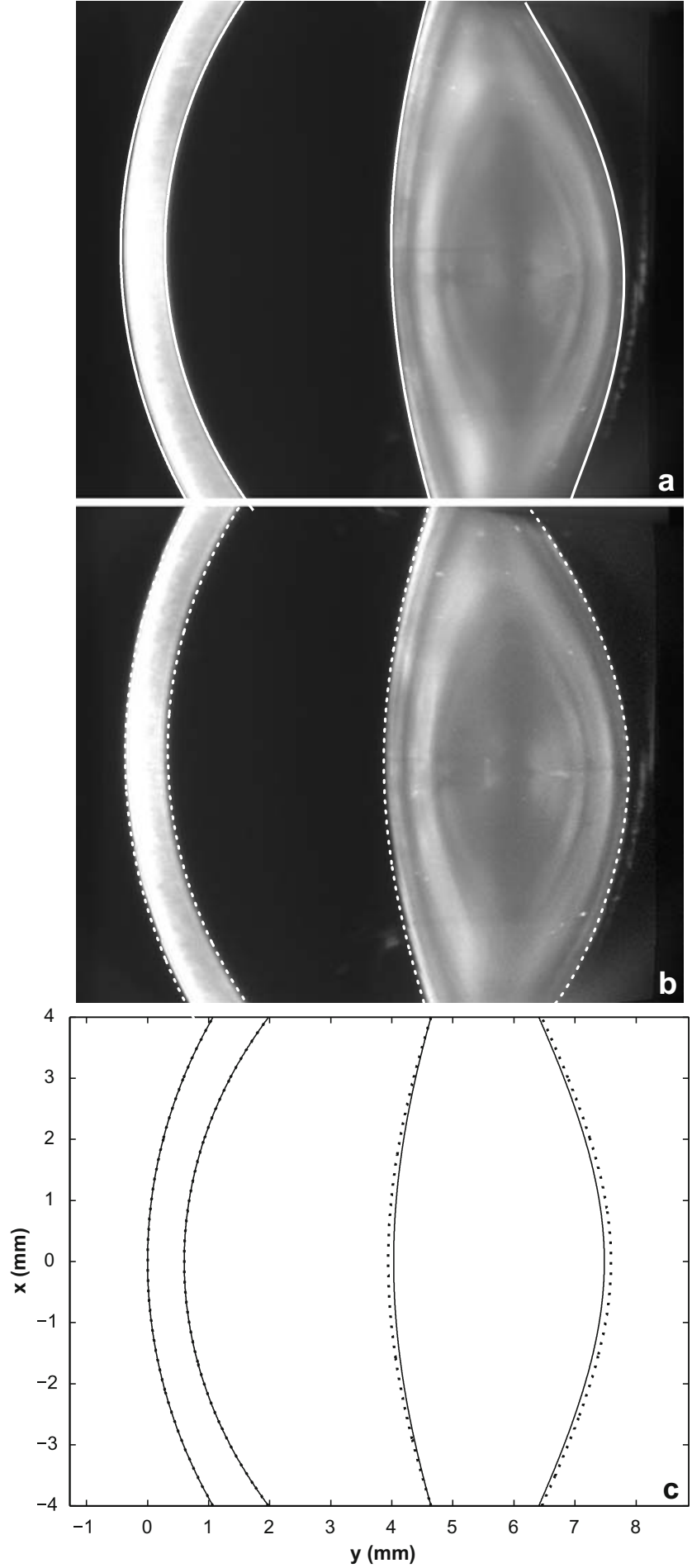

Fig. 3 Corrected Scheimpflug images of the right eye of subject 1. a At baseline time $=0$ minutes, the shape of the cornea and lens are indicated with a solid line. b During hyperglycemia at time $=240$ minutes after the first oral glucose load, the shape of the cornea and lens are indicated with a line of dashes. $\mathbf{c}$ A drawing of the changes in the shape of the lens in hyperglycemic condition (line of dashes) compared to the normal condition (solid line) subject 1 , a decrease in the equivalent refractive index of the lens was calculated during hyperglycemia. It could be suggested that if the change in the shape of the lens is small, hyperopia will predominate during hyperglycemia due to a decrease in the refractive index of the lens. Alternatively, if the change in the shape of the lens is large in comparison to the decrease in the refractive index of the lens, the overall refractive error will result in myopia. The controversy in the literature with regard to refractive changes during hyperglycemia could be explained by this underlying mechanism of a balance between changes in the shape or the refractive index of the lens, which eventually determine the overall refractive outcome [20, 23, 28, 37].

It is surprising that a change in refraction and ocular parameters could be determined in only one subject. It must be noted that the procedures for inducing hyperglycemia and monitoring blood glucose were, to some extent, different for subject 1 compared to the other subjects. Because of a delayed elevation in blood glucose level, a second oral glucose load (150 $\mathrm{g}$ instead of $75 \mathrm{~g}$ glucose) was administered. Nevertheless, the maximum blood glucose value of subject 1 did not exceed that of the other subjects, and the endogenous insulin level was adequately suppressed during the glucose loading. Furthermore, in order to obtain sufficient blood samples, $0.9 \%$ saline had to be administered to keep the antecubital vein open. Therefore, it could not be excluded that the administration of saline contributed to the refractive change and alterations in the lens of subject 1 . However, no studies have yet reported any refractive change due to saline administration.

The change in refractive error in patients with hyperglycemia could also be caused by a change in the shape of the cornea. However, previous research has shown that hyperglycemia has no influence on the shape of the anterior corneal surface [10, 24, 29, 32]. The results of our study also agree with these findings. No change in the anterior or posterior corneal radius was found during hyperglycemia. Therefore, the cornea does not seem to play a role in the explanation of refractive changes during hyperglycemia. This also applies for the higher order aberrations. Applegate et al. [1] reported that an increase in the higher order aberrations could cause a decrease in visual acuity. However, no changes in the higher order aberrations were found in any of the subjects in our study. Therefore, it can be assumed that blurred vision in hyperglycemia cannot be explained by changes in the higher order aberrations of the eye.

In sum, the results of this study show that induced hyperglycemia generally does not cause changes in the refractive properties of the healthy human eye. However, there were interindividual variations, as illustrated by subject 1, who had a hyperopic shift of refraction and a change in shape and equivalent refractive index of the lens 
during hyperglycemia. This could provide an explanation for the mechanism underlying the refractive changes often experienced by patients with DM and hyperglycemia.

Open Access This article is distributed under the terms of the Creative Commons Attribution Noncommercial License which permits any noncommercial use, distribution, and reproduction in any medium, provided the original author(s) and source are credited.

\section{References}

1. Applegate RA, Ballentine C, Gross H, Sarver EJ, Sarver CA (2003) Visual acuity as a function of Zernike mode and level of root mean square error. Optom Vis Sci 80(2):97-105

2. Birnbaum F, Leu P (1975) Acute myopia with increased intraocular pressure due to a decompensated juvenile diabetes mellitus. Klin Monatsbl Augenheilkd 167(4):613-615

3. Cheng X, Himebaugh NL, Kollbaum PS, Thibos LN, Bradley A (2003) Validation of a clinical Shack-Hartmann aberrometer. Optom Vis Sci 80(8):587-595

4. Dubbelman M, Van der Heijde GL (2001) The shape of the aging human lens: curvature, equivalent refractive index and the lens paradox. Vision Res 41(14):1867-1877

5. Dubbelman M, Van der Heijde GL, Weeber HA (2005) Change in shape of the aging human crystalline lens with accommodation. Vision Res 45(1):117-132

6. Duke-Elder S (1925) Changes in refraction in diabetes mellitus. Br J Ophthalmol 9:167-187

7. Eriksson LS, Wahren J (1989) Intravenous and subcutaneous administration of a long-acting somatostatin analogue: effects on glucose metabolism and splanchnic haemodynamics in healthy subjects. Eur J Clin Invest 19(2):213-219

8. Esenaliev RO, Larin KV, Larina IV (2001) Noninvasive monitoring of glucose concentration with optical coherence tomography. Optics Letters 26(13):992-994

9. Eva PR, Pascoe PT, Vaughan DG (1982) Refractive change in hyperglycaemia: hyperopia, not myopia. Br J Ophthalmol 66(8):500-505

10. Fledelius HC, Fuchs J, Reck A (1990) Refraction in diabetics during metabolic dysregulation, acute or chronic. With special reference to the diabetic myopia concept. Acta Ophthalmol (Copenh) 68(3):275-280

11. Furushima M, Imaizumi M, Nakatsuka K (1999) Changes in refraction caused by induction of acute hyperglycemia in healthy volunteers. Jpn J Ophthalmol 43(5):398-403

12. Gabbay KH (1973) The sorbitol pathway and the complications of diabetes. New Eng J Med 288(16):831-836

13. Giusti C (2003) Transient hyperopic refractive changes in newly diagnosed juvenile diabetes. Swiss Med Wkly 133(13-14):200-205

14. Gupta A, Casson RJ, Newland HS, Muecke J, Landers J, Selva D, Aung T (2008) Prevalence of refractive error in rural Myanmar: the Meiktila Eye Study. Ophthalmology 115(1):26-32

15. Gwinup G, Villarreal A (1976) Relationship of serum glucose concentration to changes in refraction. Diabetes 25(1):29-31

16. Herse P (2005) Effects of hyperglycaemia on ocular development in rabbit: refraction and biometric changes. Ophthalmic Physiol Opt 25(2):97-104

17. Huggert A (1954) The appearance of the crystalline lens during different stages of transitory changes of refraction. Acta Ophthalmol (Copenh) 32(4):375-389
18. Imai T, Matsuda M (1992) Refractory changes of the eyes in NIDDM during treatment. Quantitative analysis. Diabetes Care 15 (7):938-939

19. Kato S, Oshika T, Numaga J, Kawashima H, Kitano S, Kaiya T (2000) Influence of rapid glycemic control on lens opacity in patients with diabetes mellitus. Am J Ophthalmol 130(3):354 355

20. Keller JT (1973) A mechanism for refractive changes in diabetes. Am J Optom Physiol Opt 50(2):108-111

21. Kluxen G, Scholz A (1987) Evaluation of Scheimpflug photographs in transitory hypermetropia. Klin Monatsbl Augenheilkd 191(2):129-132

22. Kohl M, Cope M (1994) Influence of glucose concentration on light scattering in tissue-simulating phantoms. Optics Letters 19 (24):2170-2172

23. Mäntyjärvi M (1988) Myopia and diabetes. A review. Acta Ophthalmol Suppl 185:82-85

24. Okamoto F, Sone H, Nonoyama T, Hommura S (2000) Refractive changes in diabetic patients during intensive glycaemic control. $\mathrm{Br}$ J Ophthalmol 84(10):1097-1102

25. Pierro L, Brancato R, Zaganelli E, Guarisco L, Calori G (1996) Correlation of lens thickness with blood glucose control in diabetes mellitus. Acta Ophthalmol Scand 74(6):539-541

26. Planten JT (1975) Physiologic optic approach of lens and cataract. Ophthalmologica 171(4-5):249-253

27. Planten JT, Kooijman AC, De Vries B, Woldringh JJ (1978) Pathological-optic approach of cataract and lens. Ophthalmologica 176(6):331-334

28. Planten J (1981) Changes of refraction in the adult eye due to changing refractive indices of the layers of the lens. Ophthalmologica 183(2):86-90

29. Saito Y, Ohmi G, Kinoshita S, Nakamura Y, Ogawa K, Harino S, Okada M (1993) Transient hyperopia with lens swelling at initial therapy in diabetes. Br J Ophthalmol 77(3):145-148

30. Salmon TO, Van de Pol C (2005) Evaluation of a clinical aberrometer for lower-order accuracy and repeatability, higherorder repeatability, and instrument myopia. Optometry 76(8):461472

31. Sjølie AK, Mortensen KK, Hecht PS, Eshøj O (1991) Visual acuity and refraction in type I diabetic patients aged 25-34 years. Acta Ophthalmol (Copenh) 69(4):552-554

32. Sonmez B, Bozkurt B, Atmaca A, Irkec M, Orhan M, Aslan U (2005) Effect of glycemic control on refractive changes in diabetic patients with hyperglycemia. Cornea 24(5):531-537

33. Tai MC, Lin SY, Chen JT, Liang CM, Chou PI, Lu DW (2006) Sweet hyperopia: refractive changes in acute hyperglycemia. Eur J Ophthalmol 16(5):663-666

34. Thibos LN, Applegate RA, Schwiegerling JT, Webb R (2002) VSIA Standards Taskforce Members. Vision science and its applications. Standards for reporting the optical aberrations of eyes. J Refract Surg 18(5):S652-S660

35. Thibos LN, Hong X, Bradley A, Applegate RA (2004) Accuracy and precision of objective refraction from wavefront aberrations. J Vis 4(4):329-351

36. Turtz CA, Turtz AI (1958) Reversal of lens changes in early diabetes. Am J Ophthalmol 46(2):219

37. Varma SD, El-Aguizy HK, Richards RD (1980) Refractive change in alloxan diabetic rabbits. Control by flavonoids I. Acta Ophthalmol (Copenh) 58(5):748-759

38. Wang Q, Klein BE, Klein R, Moss SE (1994) Refractive status in the Beaver Dam Eye Study. Invest Ophthalmol Vis Sci 35 (13):4344-4347 